\title{
The intensive care unit in paediatric oncology
}

\author{
D Heney, I J Lewis, L Lockwood, A T Cohen, C C Bailey
}

\begin{abstract}
There were 70 admissions from a regional paediatric oncology centre to the intensive care unit over a six and a half year period. Patients were divided into those with systemic infections $(n=19)$, respiratory infections $(n=15)$, metabolic effects $(n=9)$, tumour mass effects $(n=10)$, neurological complications $(n=8)$, and others $(n=9)$. The overall survival was $51 \%$. Patients admitted with metabolic or tumour mass related effects had the best prognosis with a survival of $\mathbf{8 4 \%}$. If dialysis is required in this group of patients then continuous arteriovenous haemofiltration is recommended. Patients with systemic or respiratory infections comprised the main poor prognosis group with a survival of $26 \%$. For patients with a systemic infection who required ventilation, the mortality was $100 \%$. The outlook for patients with a generalised encephalopathy was also poor, with no neurologically intact survivors. The median APACHE-II (acute physiology and chronic health evaluation) score for patients who died was 27 and for survivors was 16. There is a need for close cooperation between staff of intensive care and paediatric oncology units. Alternative treatments should be considered for patients with systemic infections who require ventilation.
\end{abstract}

Over the past 15 years, with the introduction of increasingly intensive protocols, the nature of paediatric oncology has changed significantly. This has been accompanied by improved survival figures for children with both haematological and solid malignancies. It has, however, resulted in children spending extended periods in hospital with severe and life threatening complications of their malignancy and/or the associated treatment. Close cooperation with an intensive care facility is therefore an essential part of any regional oncology centre. Admission to an intensive care unit has many costs that include emotional and social factors, as well as those that are medical and financial in nature. An understanding of the benefits of an intensive care unit is therefore important for decision making and for counselling of the families involved. It was for these reasons that we undertook the present study.

Patients and methods

This study was performed over a six and a half year period, from July 1984 to December 1990. Details were recorded of all patients from the paediatric oncology unit at St James's University Hospital, Leeds, who required admission to the intensive care unit (ICU). The information used in this study was collected contemporaneously by the ICU, and was then clarified by retrospective chart review. There were a total of 65 patients admitted on 70 occasions in the study. Their underlying oncological diagnoses are given in table 1 . Their mean age was 6.6 years (range 2 months-14.5 years), and there were 39 boys and 26 girls.

The paediatric oncology unit is a regional unit, serving Yorkshire and Humberside. There are on average 100 new patients presenting with primary malignancies each year. The only patients not included in this study were those requiring specialised neurosurgery, who were operated on at two nearby, regional neurology centres. However, many received subsequent medical treatment at St James's University Hospital.

The ICU is a combined adult and paediatric unit. Admission to the ICU is restricted by bed availability, and our oncology ward is capable of functioning as a high dependency unit. The nursing staff on the oncology ward have not received an intensive care training but frequently care for acutely ill children. Patients are admitted to the ICU when they require respiratory support, cardiovascular support, or complex monitoring. We have standard policies on our ward for the treatment of febrile neutropenia and for patients presenting with tumour lysis syndrome and airway obstruction.

All febrile neutropenic patients receive early treatment with broad spectrum antibiotics, with haematological support where necessary. If signs of endotoxic shock are present with hypotension, tachycardia, poor peripheral circulation, and reduced urine output then plasma expanders are used. If a rapid response is not obtained inotropic agents are given, initially as low dose dopamine. Providing patients are stable, with restitution of blood pressure, improved circulation, and increased urine output they will continue to be treated on

Table 1 Survival by oncological diagnosis

\begin{tabular}{lcc}
\hline Diagnosis & $\begin{array}{l}\text { No of } \\
\text { cases }\end{array}$ & $\begin{array}{l}\text { No (\%) } \\
\text { surviving }\end{array}$ \\
\hline $\begin{array}{l}\text { Acute lymphoblastic leukaemia } \\
\text { Acute myeloid luekaemia }\end{array}$ & 30 & $12(40)$ \\
Non-Hodgkin's lymphoma & 9 & $5(56)$ \\
Hodgkin's lymphoma & 13 & $9(69)$ \\
Juvenile chronic & 1 & 1 \\
$\begin{array}{l}\text { granulocytic leukaemia } \\
\text { Histiocytosis }\end{array}$ & 2 & 0 \\
Solid tumours & 2 & 0 \\
Total & 13 & $9(69)$ \\
\hline
\end{tabular}

\author{
Correspondence to: \\ Dr I J Lewis, \\ Paediatric Oncology, \\ St James's University
Hospital, Leeds LS9 7TF. \\ Accepted 15 October 1991 \\ St James' Unive \\ Paediatrics \\ I J Lewis \\ C C Bailey \\ Department of \\ Intensive Care
}


the ward. Transfer to the ICU is sought if a response is not obtained and/or double inotropic support (dopamine/dobutamine) is required.

Patients with the potential for developing tumour lysis syndrome are treated on the ward with allopurinol, hydration, and alkalinisation of their urine. Chemotherapy is withheld until their metabolic status has been stabilised. Patients are transferred to the ICU when indicated or if deterioration is anticipated.

The APACHE-II (acute physiology and chronic health evaluation) severity of disease score was assessed by the ICU staff on the basis of the first 24 hours after admission. ${ }^{1}$ The difference between medians was calculated using the Mann-Whitney $U$ test. The other information collected prospectively included age, sex, date of admission and discharge, reason for admission, treatment delivered in the ICU and the outcome. Patients with a successful outcome were defined as those who were alive one week after leaving the ICU. Duration of stay in the ICU was calculated as a whole day providing the patient was in the ICU for greater than 12 hours of that day. If the patient was in the ICU for more than one day, the day of discharge was not included in the duration of stay calculation.

\section{Results}

Over the six and a half years there were 70 paediatric oncology admissions to the ICU. The overall survival was $51 \%$. Survival by oncological diagnosis is shown in table 1 . Of the 13 patients with non-Hodgkin's lymphoma nine were admitted for metabolic and/or tumour effects. Survival was $89 \%$ for these nine patients. Survival for children with acute lymphoblastic leukaemia (ALL) was the lowest, being $40 \%$, but this diagnostic group contained the highest proportion of infected patients $(67 \%)$.

Survival by reason for admission to the ICU is shown in table 2. A number of patients had multiple pathologies. However, they were allocated to a group by their most important or dominant pathology.

\section{SYSTEMIC INFECTIONS}

The largest group consisted of 19 patients with systemic infections. Twelve of these patients had a Gram negative septicaemia with the following organisms cultured: Escherichia coli in six, Pseudomonas aeruginosa in three, Klebsiella spp in two and Bacteroides fragilis in one. A single patient had a possible Gram positive infection with enterobacter isolated, although its significance is unclear as it was only isolated in the mid-course of the illness. There were two systemic viral infections with herpes zoster and herpes simplex. There were three systemic fungal infections, with disseminated aspergillus in two and disseminated candidiasis in one. There was one patient in whom no organism was isolated.

The patients with Gram negative infections all presented with endotoxic shock unresponsive to initial management. In all cases they received intravenous antibiotics to which the organism was sensitive but continued to deteriorate clinically. All 12 received inotropic support with combined dopamine and dobutamine, and two required renal dialysis. Nine of the 12 patients were ventilated and all nine died. One of the ventilated patients developed adult respiratory distress syndrome (ARDS), becoming ventilator dependent and dying of respiratory failure. Three patients with Gram negative infections were not ventilated, and survived. No single indication for ventilation was used. Rather, ventilation was instituted on the basis of a combination of deranged blood gases, increased respiratory rate, clinical exhaustion, and altered level of consciousness.

The seven patients with other systemic, nonbacterial infections all required ventilation and subsequently died due to the primary infection. Six of these patients required inotropic support and three were dialysed. Invasive monitoring used for all patients with systemic or respiratory infections included both arterial access and central venous catheters. Pulmonary arterial catheters were not used. There was no additional serious morbidity related to the monitoring.

\section{RESPIRATORY INFECTIONS}

There were 15 patients with respiratory infections. The largest group were fungal, with six aspergillus and one candida infection. There were three viral infections with Varicella zoster, parainfluenzae, and giant cell pneumonitis. Three patients had presumed pneumocystis pneumonia with typical clinical and radiological features. In two patients there was no clear aetiology. The overall mortality for this group was $60 \%$, being higher for the ventilated patients $(73 \%)$. Six patients in this group required inotropic support and all six died.

Table 2 Survival by reason for admission. Results are number or number (\%)

\begin{tabular}{|c|c|c|c|c|c|c|c|}
\hline \multirow{3}{*}{$\begin{array}{l}\text { Reason for } \\
\text { admission }\end{array}$} & \multirow{3}{*}{$\begin{array}{l}\text { No of } \\
\text { patients }\end{array}$} & \multirow{2}{*}{$\begin{array}{l}\text { Invasive } \\
\text { monitoring }\end{array}$} & \multirow[t]{2}{*}{ Inotropes } & \multirow{2}{*}{$\begin{array}{l}\text { Renal } \\
\text { dialysis }\end{array}$} & \multicolumn{3}{|l|}{ Survival } \\
\hline & & & & & Ventilated & \multicolumn{2}{|c|}{ Not ventilate } \\
\hline & & $\begin{array}{l}19(100) \\
15(100)\end{array}$ & $\begin{array}{r}18 \\
6\end{array}$ & $\begin{array}{l}5 \\
0\end{array}$ & $\begin{array}{l}0 / 16 \quad(0) \\
3 / 11(27)\end{array}$ & $\begin{array}{l}3 / 3 \\
3 / 4\end{array}$ & $\begin{array}{r}(100) \\
(75)\end{array}$ \\
\hline $\begin{array}{l}\text { Metabolic effect } \\
\text { Tumour mass effect }\end{array}$ & $\begin{array}{r}9 \\
10\end{array}$ & $\begin{array}{ll}7 & (78) \\
9 & (90)\end{array}$ & $\begin{array}{l}0 \\
0\end{array}$ & $\begin{array}{l}3 \\
0\end{array}$ & $\begin{array}{ll}3 / 5 & (60) \\
3 / 4 & (75)\end{array}$ & $\begin{array}{l}4 / 4 \\
6 / 6\end{array}$ & $\begin{array}{l}(100) \\
(100)\end{array}$ \\
\hline $\begin{array}{l}\text { Neurological } \\
\text { Postoperative }\end{array}$ & $\begin{array}{l}8 \\
5\end{array}$ & $\begin{array}{ll}6 & (75) \\
3 & (60)\end{array}$ & $\begin{array}{l}\mathbf{0} \\
\mathbf{0}\end{array}$ & $\begin{array}{l}0 \\
0\end{array}$ & $\begin{array}{ll}3 / 5 & (60) \\
2 / 3 & (67)\end{array}$ & $\begin{array}{l}2 / 3 \\
2 / 2\end{array}$ & $\begin{array}{r}(67) \\
(100)\end{array}$ \\
\hline $\begin{array}{l}\text { Postcardiac arrest } \\
\text { Gastrointestinal bleed } \\
\text { Cardiac faiure }\end{array}$ & $\begin{array}{l}2 \\
1 \\
1\end{array}$ & $\begin{array}{l}2 \\
1 \\
1\end{array}$ & $\begin{array}{l}1 \\
0 \\
1\end{array}$ & $\begin{array}{l}0 \\
0 \\
0\end{array}$ & $\begin{array}{ll}0 / 2 & (0) \\
- & \end{array}$ & $\overline{1 / 1}$ & \\
\hline Total & 70 & $63(90)$ & 26 & 8 & $14 / 46$ & $22 / 24$ & $(92)$ \\
\hline
\end{tabular}


METABOLIC EFFECTS

Details of patients presenting with metabolic effects are shown in table 3. Two of the patients required dialysis for tumour lysis syndrome with progressive hyperphosphataemia, hypocalcaemia, and reduced urine output. Both were treated with continuous arteriovenous haemofiltration which provided satisfactory metabolic and fluid control. Two patients developed symptomatic hyperkalaemia resulting in a cardiac arrest. Although one patient was resuscitated he remained severely neurologically handicapped and subsequently died of progressive disease.

\section{IMPAIRED VENTILATION DUE TO TUMOUR MASS} EFFECTS

Ten patients were admitted with impaired ventilation due to tumour mass effects (table 4), and included those with airway obstruction, and respiratory or cardiovascular compromise secondary to their tumour. Only one out of the 10 patients died. The overall survival for patients admitted to the ICU with metabolic or ventilation related tumour problems was $84 \%$.

\section{NEUROLOGICAL EFFECTS}

Eight patients were admitted with primarily neurological disease (table 5). Only two patients survived neurologically intact and in both the disease was localised and reversible. The outlook for patients with generalised encephalopathy was poor.

\section{OTHERS}

Two patients were admitted after a cardiac arrest on the ward. Only one survived, but he remained severely neurologically handicapped and died of progressive disease. The remaining details are shown in table 2 .

Table 3 Metabolic effects

\begin{tabular}{|c|c|c|c|c|c|}
\hline No & Diagnosis & Reason for admission & Dialysis & Ventilation & Outcome \\
\hline 1 & NHL & $\begin{array}{l}\text { Tumour lysis syndrome, } \\
\text { incipient ARF }\end{array}$ & Yes & No & Survived \\
\hline 2 & NHL & $\begin{array}{l}\text { Tumour lysis syndrome, } \\
\text { incipient ARF }\end{array}$ & Yes & No & Survived \\
\hline 3 & NHL & $\begin{array}{l}\text { Tumour lysis syndrome, } \\
\text { incipient ARF }\end{array}$ & No & No & Survived \\
\hline 4 & NHL & $\begin{array}{l}\text { Tumour lysis syndrome, } \\
\text { hyperkalaemia, cardiac arrest }\end{array}$ & No & Yes & $\begin{array}{l}\text { Survived with severe } \\
\text { neurological handicap }\end{array}$ \\
\hline 5 & ALL & $\begin{array}{l}\text { Tumour lysis syndrome } \\
\text { hyperkalaemia }\end{array}$ & No & Yes & Died \\
\hline 6 & ALL & $\begin{array}{l}\text { High white cell count, } \\
\text { anaemia (haemoglobin } 2 \mathrm{~g} / \mathrm{l} \text { ), } \\
\text { acidosis (pH } 6 \cdot 7 \text { ) }\end{array}$ & No & Yes & Survived \\
\hline 7 & $\begin{array}{l}\text { Malignant fibrous } \\
\text { histiocytoma }\end{array}$ & $\begin{array}{l}\text { Ifosfamide induced acute } \\
\text { Fanconi's syndrome, acidosis }\end{array}$ & No & Yes & Survived \\
\hline 8 & Wilms' tumour & $\begin{array}{l}\text { Actinomycin induced, } \\
\text { hepatorenal failure }\end{array}$ & Yes & Yes & Died \\
\hline 9 & Hepatoblastoma & $\begin{array}{l}\text { Adriamycin induced } \\
\text { gastrointestinal toxicity }\end{array}$ & No & No & Survived \\
\hline
\end{tabular}

NHL, non-Hodgkin's lymphoma; ALL, acute lymphoblastic leukaemia; ARF, acute renal failure.

Table 4 Tumour effects with impaired ventilation

\begin{tabular}{|c|c|c|c|c|}
\hline No & Diagnosis & Reason for admission & Ventilated & Outcome \\
\hline 1 & NHL & $\begin{array}{l}\text { Mediastinal compression, } \\
\text { airway obstruction }\end{array}$ & Yes & Survived \\
\hline 2 & NHL & $\begin{array}{l}\text { Pleural effusion } \\
\text { pulmonary oedema }\end{array}$ & Yes & Survived \\
\hline 3 & NHL & $\begin{array}{l}\text { Mediastinal compression, tumour } \\
\text { invading heart, cardiac arrest }\end{array}$ & Yes & Died \\
\hline $\begin{array}{l}4 \\
5 \\
6\end{array}$ & $\begin{array}{l}\text { NHL } \\
\text { NHL } \\
\text { ALL }\end{array}$ & $\begin{array}{l}\text { Upper airway obstruction } \\
\text { Mediastinal compression } \\
\text { Mediastinal compression, }\end{array}$ & $\begin{array}{l}\text { No } \\
\text { No } \\
\text { No }\end{array}$ & $\begin{array}{l}\text { Survived } \\
\text { Survived } \\
\text { Survived }\end{array}$ \\
\hline 7 & ALL & $\begin{array}{l}\text { Mediastinal compression, pleural } \\
\text { effusion, airway obstruction }\end{array}$ & No & Survived \\
\hline 8 & Neuroblastoma & $\begin{array}{l}\text { Abdominal mass, diaphragmatic } \\
\text { splinting }\end{array}$ & Yes & Survived \\
\hline 9 & Neuroblastoma & $\begin{array}{l}\text { Abdominal mass, diaphragmatic } \\
\text { splinting }\end{array}$ & No & Survived \\
\hline 10 & Rhabdomyosarcoma & $\begin{array}{l}\text { Abdominal mass, diaphragmatic } \\
\text { splinting }\end{array}$ & No & Survived \\
\hline
\end{tabular}

NHL, non-Hodgkin's lymphoma; ALL, acute lymphoblastic leukaemia.

Table 5 Neurological disease

\begin{tabular}{|c|c|c|c|c|}
\hline No & Diagnosis & Reason for admission & Ventilation & Outcome \\
\hline 1 & Neuroblastoma & $\begin{array}{l}\text { Cord compression, } \\
\text { convulsions }\end{array}$ & Yes & Survived neurologically intact \\
\hline 2 & $\begin{array}{l}\text { ALL } \\
\text { ALL }\end{array}$ & $\begin{array}{l}\text { Central nervous system deposits, } \\
\text { Radiotherapy related ascending } \\
\text { myelitis }\end{array}$ & $\begin{array}{l}\text { No } \\
\text { Yes }\end{array}$ & $\begin{array}{l}\text { Survived neurologically intact } \\
\text { Survived with severe neurological handicap }\end{array}$ \\
\hline 4 & ALL & Herpes encephalitis & Yes & $\begin{array}{l}\text { Survived with severe neurological handicap, } \\
\text { died of relapsed disease }\end{array}$ \\
\hline 3 & $\begin{array}{l}\text { ALL } \\
\text { ALL } \\
\text { AML } \\
\text { PNET }\end{array}$ & $\begin{array}{l}\text { Encephalopathy ? drug induced } \\
\text { Encephalopathy } \\
\text { Intracerebral bleed } \\
\text { Intracerebral bleed }\end{array}$ & $\begin{array}{l}\text { No } \\
\text { No } \\
\text { Yes } \\
\text { Yes }\end{array}$ & $\begin{array}{l}\text { Survived with severe neurological handicap } \\
\text { Died } \\
\text { Died } \\
\text { Died }\end{array}$ \\
\hline
\end{tabular}

ALL, acute lymphoblastic leukaemia; AML, acute myeloblastic leukaemia; PNET, primitive neuroectodermal tumour. 


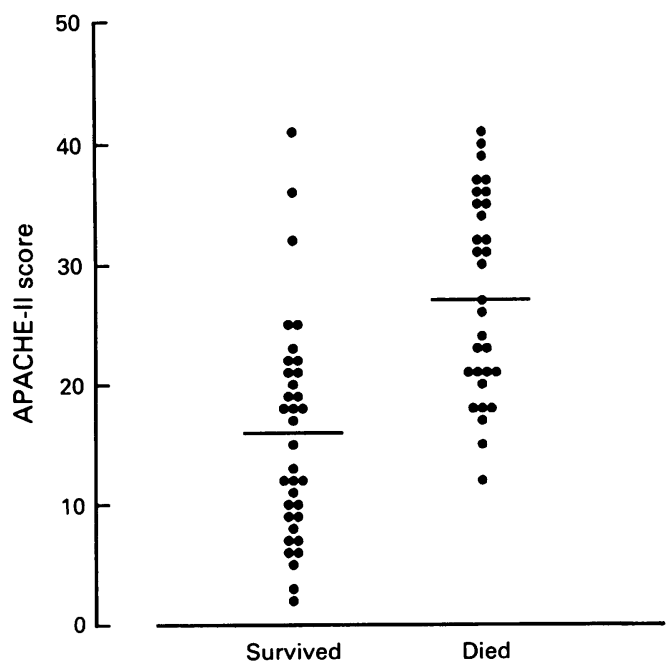

APACHE-II severity of disease score. The horizontal line is the median value.

The APACHE-II severity of illness scores, evaluated over the first 24 hours, are shown in the figure. The median score for those who survived was 16 and for those who died was 27. The $95 \%$ confidence interval for difference between medians was 7 to $16(p<0.001)$. The three patients with APACHE-II scores greater than 30 who survived included a patient with ALL with tumour and metabolic effects; a patient with ALL with acute renal failure and a respiratory infection; and a patient with acute myeloblastic leukaemia (AML) who suffered hypoxia after general anaesthesia.

For all patients, the mean duration of stay in the ICU was 6 days, with a range of 1 to 56 days.

\section{Discussion}

This report documents our experience in the use of an intensive care unit by a regional paediatric oncology centre. There are few studies in the literature examining the role of an intensive care unit in this setting. Most are applicable only to adult oncology units, and there is a large variation in results and the conclusions drawn from these studies. ${ }^{2-5}$ The only similar paediatric report comes from a combined study of three hospitals in Australia and Canada. ${ }^{6}$

The overall survival for all children in this study was $51 \%$. The mortality was higher for those children who required ventilation, where there was only a $30 \%$ survival. Of those patients not ventilated two subsequently died. For both, an elective decision was made, after admission to the ICU, not to continue with active treatment because of progressive disease. All the remaining patients, who were not ventilated, survived.

The mortality, for patients admitted with a systemic infection, was $84 \%(16 / 19)$. Three patients who did not require ventilation were the only survivors. For those patients with a systemic infection who required ventilation, the mortality was therefore $100 \%$. Febrile neutropenia is a common indication for admission to our oncology ward. We have an aggressive management policy for these patients, and the overall survival is in the order of $98 \% .{ }^{7}$ Patients are treated early with broad spectrum antibiotics and receive haematological and cardiovascular support when necessary. The septicaemic patients admitted to the ICU in our study therefore represent those patients where initial intensive therapy had failed and in whom cardiovascular and/or ventilatory support was required.

The majority of febrile neutropenic patients in whom a bacteraemia is diagnosed have a Gram positive infection. ${ }^{7}$ There were no deaths due to proved Gram positive infections during this period, confirming the low mortality, although high morbidity, associated with these infections. By contrast, Gram negative infections, although fewer in number, remain difficult to control and are associated with a significant mortality.

We are concerned that all ventilated septicaemic patients died. Our experience is similar to that described by Butt $e t$ al who also reported a high mortality for these patients. ${ }^{6}$ We reviewed in detail the case notes of the septicaemic patients in an attempt to identify factors that may have contributed to the patients' deaths. Factors examined included the time from the onset of marked cardiovascular symptoms to the use of inotropes, the subsequent time to admission to the ICU and to intubation, the indications for intubation, and the time the patient died. There were no common patterns. In four patients a possible factor may have been the delayed use of inotropes which were given more than 24 hours after the onset of marked cardiovascular symptoms, and it is now our practice to use inotropes earlier in the course of the disease. The early use of volume replacement together with low dose dopamine is therefore instituted on the oncology ward in appropriate patients. Admission to the ICU is then considered if the patient's condition remains unstable or if increased inotropic doses or double inotropic agents are required. If the prognosis is to be improved then alternative strategies need to be considered. It is in this group of patients that new therapies such as antiendotoxin antibodies should be evaluated. ${ }^{8}$

The best prognosis was seen in those children admitted with metabolic or tumour related effects. Although some of these children had high APACHE-II scores, their short term outlook is good provided their acute complications can be resolved. Patients with non-Hodgkin's lymphoma or acute lymphoblastic leukaemia presenting with a large mediastinal or abdominal mass are at risk for both tumour lysis syndrome and compression of airways or vital organs.

The true extent of airway obstruction may be difficult to assess and may be missed on anteroposterior chest radiographs. A penetrated lateral radiograph is recommended. ${ }^{9}$ Clinical signs may also be misleading and obstruction may develop suddenly and without warning. General anaesthesia for diagnostic procedures is an important risk factor, with obstruction often presenting for the first time after the anaesthetic. ${ }^{10}$ If general anaesthesia is required it 
should be performed by an anaesthetist skilled in the management of airway problems in children.

Tumour lysis syndrome is usually precipitated by cytotoxic chemotherapy, but can occur before treatment starts due to spontaneous lysing of lymphoblasts. Cytotoxic chemotherapy should preferably not be instituted until the patient's metabolic parameters have been stabilised. There has been increased recognition of the importance of hyperphosphataemia as a cause of acute renal failure, with lymphoblasts containing four times more phosphate than mature lymphocytes. Calcium phosphate crystals may be precipitated, resulting in renal tissue damage, renal tubular obstruction and metastatic calcification. Hypocalcaemia is an invariable consequence which may itself be symptomatic. The incidence of hyperkalaemia has been low in recently reported series due to improved fluid and acid-base management. ${ }^{11}$ Nevertheless, hyperkalaemia remains potentially the most lethal complication with rapid rises in plasma potassium resulting in sudden death.

If standard conservative management fails to control metabolic parameters, then patients should be considered for early institution of renal dialysis. Although haemodialysis permits the correction of plasma electrolyte concentrations, there is still the possibility of large swings in plasma levels between treatments. In acutely ill patients there is also the potential complication of the disequilibrium syndrome and haemodynamic compromise. We therefore recommend the use of continuous arteriovenous haemofiltration (CAVH), ${ }^{12}$ or haemodiafiltration if clearance is inadequate. CAVH was used to treat patients numbers 2 and 3 (table 3); it allows for the removal of large fluid volumes facilitating the concomitant administration of obligatory intravenous fluids. It is also haemodynamically gentle and provides a steady and continuous correction of metabolic parameters. Our ICU has since used venovenous haemofiltration which has fewer problems related to clotting of the filter.

The APACHE-II severity of disease classification, or similar scoring system, is widely used in many intensive care units. We acknowledge that the APACHE-II was not designed for children and that other systems such as the Admission Physiological Stability Index or the Organ System Failure Score are more appropriate. ${ }^{13}$ Nevertheless the APACHE-II will still be used in many combined paediatric and adult units. Although patients who died had a significantly higher median APACHE-II score on admission, there was a large overlap. The APACHE-II score alone could not be used to predict the outcome for individual patients.

The decision to admit patients to the ICU is a complex process. Although the clinical status of the patient is the predominating factor, it is strongly influenced by the availability of intensive care beds as well as the capabilities of staff on the oncology unit and psychological pressures imposed by parents and staff. Patients whose condition requires ventilation or patients receiving double inotropes would form an absolute indication for admission to the ICU. More difficult questions arise where there is an increased need for monitoring and support without initial ventilation. Ideally we have tried to adopt a policy whereby, if early supportive measures fail, we initiate discussion with our intensivists. Within this study we are not aware of any children who were not admitted to our ICU if they fulfilled the above criteria. However, with the increased demand on ICU space and the greater intensity of paediatric oncology schedules, this becomes more of a possibility. Corresponding demands are placed on the oncology ward for the care of these acutely ill children.

Youngner et al have highlighted problems in attitude and misunderstanding which may exist between an oncology unit and the ICU, with resulting communication breakdown. ${ }^{14}$ In order to offer the possibility of survival using modern intensive care techniques, it is essential to develop close working relationships between paediatric oncology and intensive care teams. This will allow for flexibility in decision making, providing sympathetic care that is in the best interest of the patients and their families. In addition, high risk groups, such as patients with Gram negative infections requiring ventilation, can be identified and new approaches evaluated.

This study was supported by the Candlelighters' Trust. We wish to thank the nursing and medical staff on the ICU for their dedication and care.

1 Knaus WA, Draper EA, Wagner DP, Zimmerman JE. APACHE-II: a severity of disease classification system. Crit Care Med 1985;13:818-29.

2 Lloyd-Thomas AR, Wright I, Lister TA, Hinds CJ. Prognosis of patients receiving intensive care for life threatening medical complications of haematological malignancy. $B M \mathcal{F}$ 1988;296:1025-9.

3 Sculier JP, Ries F, Verboven N, Coune A, Klastersky J. Role of intensive care unit in a medical oncology department. Eur f Cancer Clin Oncol 1988;24:513-7.

4 Ashkenazi YJ, Baranett SK, Haraman E. Short-term outcome among patients with leukemia and lymphoma admitted to a medical intensive care unit. South Med $\mathcal{F} 1986 ; 79$ : to a medic

5 Johnson MH, Gordon PW, Fitzgerald FT. Stratifiction of prognosis in granulocytopenic patients with hematologic malignancies using the APACHE-II severity of illness score. Crit Care Med 1986;14:693-7.

6 Butt W, Barker G, Walker C, et al. Outcome of children with hematologic malignancy who are admitted to an intensive care unit. Crit Care Med 1988;16:761-4.

7 Heney D, Lewis IJ, Ghoneim ATG, Chisholm P, Bailey CC. Aztreonam therapy in children with febrile neutropenia; a randomised trial of aztreonam plus flucloxacillin versus piperacillin plus gentamicin. $\mathcal{F}$ Antimicrob Chemother 1991; 28:117-29.

8 Ziegler EJ, Fisher CJ, Sprung CL, et al. Treatment of Gramnegative bacteraemia and septic shock with HA-1A human monoclonal antibody against endotoxin: a randomized, double-blind, placebo controlled trial. $N$ Engl $f \mathrm{Med}$ 1991;324:429-36.

9 Shaw EA. Mediastinal tumours causing airway obstruction. Anaesthesia 1983;38:66-7.

10 Jeffery GM, Mead GM, Whitehouse JMA. Life-threatening airway obstruction at the presentation of Hodgkin's disease.

11 Stapleton FB, Strother DR, Roy S, Wyatt RJ, McKay CP, Murphy SB. Acute renal failure at onset of therapy for Murphy SB. Acute renal failure at onset of therapy for advanced stage Burkitt lymphoma and B cell acute

12 Heney D, Essex-Cater A, Brocklebank JT, Bailey CC, Lewis IJ. Continuous arteriovenous haemofiltration in the treatment of tumour lysis syndrome. Pediatr Nephrol 1990;4: 245-7.

13 Price HL, Matthew DJ. Evaluation of pediatric intensive care scoring systems. Intensive Care Med 1989;15:79-83.

4 Youngner SJ, Allen M, Montenegro H, Hreha J, Lazarus $H$. Resolving problems at the intensive care unit/oncology unit interface. Perspect Biol Med 1988;31:299-308. 